\title{
Estimating of times and Heliospheric Location of the accelerated energetic protons associated with two CMEs in the Multi Eruption Solar Energetic Particle (MESEPs) events
}
D.Al-Feadh ${ }^{1}$
A.Al-Sawad ${ }^{2}$
W.Al-Ramdhan ${ }^{1}$
E. Valtonen ${ }^{2}$

'Department of physics, Faculty of science, University of Basra, Karmat Ali B.P 49, Basra, Iraq

`Department of physics and Astronomy, Turku University, FIN 20014 Turku, Finland.

\begin{abstract}
$\underline{\text { Abstract }}$
We have selected two Multi Eruption Solar Energetic Particle (MESEP) events among 268 MESEP events during the solar cycle 23 observed by Energetic and Relativistic Nuclei and Electron (ERNE) instrument on board Solar and Heliospheric Observatory (SOHO) with intensities of $>10-3 \mathrm{~cm}-2$ sr-1 s-1 MeV-1 at energies (1-116) MeV. We have estimated the time and place of the acceleration for the energetic protons injected by two Coronal Mass Ejection (CMEs) associated with each MESEP event. We have calculated the injection time of the energetic protons by using the fixed path length and the Velocity Dispersion Analysis (VDA) methods, assuming that particles with different energies were released simultaneously at the Sun. We found that in both methods the bulk of the acceleration occur during the impulsive phase near the Sun.
\end{abstract}

Key word: - coronal mass ejection, multi Eruption Solar Energetic Particle (MESEP)

تقدير موقع ووقت التعجيل للبروتونات النشطة المتحرة بواسطة كتل الاهليل الشمسي المرافقة للأحداث الشمسية ذات الانفجارات المزدوجة ( MESEPs )

واثق الرمضان ا اينو فالتونين ب

امجد السوادץ

$$
\begin{aligned}
& \text { 1 جامعة البصرة- كلية العلوم- قسم الفيزياء } \\
& \text { r ف فلندا، توركو - جامعة توركو - قسم الفيزياء والفلكي }
\end{aligned}
$$

الخلاصة

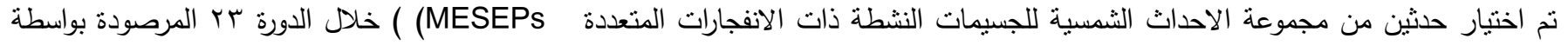

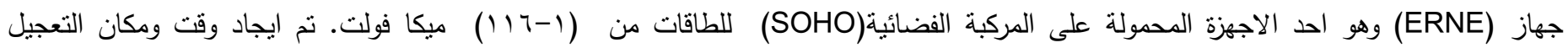

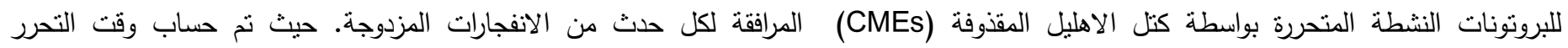
(VDA) بافتراض ان الجسيمات ذات الطاقات (injection time)

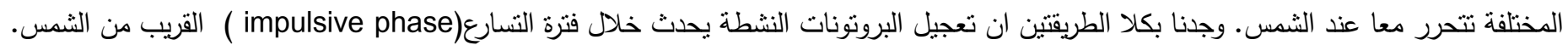




\section{Introduction}

SEPs in their intensity-time profile, energy spectra, elemental, isotopic, and ionic charge composition carry fundamental information on the source region of their acceleration and propagation processes the occurrence of SEP events is directly related to flares and coronal mass ejections (CMEs) [1] and with interplanetary shocks [2]. Coronal mass ejections (CMEs) are known to be of the most important coronal phenomena contributing to interplanetary solar wind disturbances. Dynamical parameters of CMEs are directly involved on the possible effects on space weather conditions [3].

The observation of the first non-scattered relativistic particles is one tool to establish the connection between sudden rise in the intensity-time profile for many particle species which occur after flares or CMEs [2]. Note that these measurements are background dependent unless the background of the intensity-time profile is clear enough and not masked by previous events, the exact association of the SEP events with the eruption cannot be accurate. In this manner it is not possible know whether the CMEs or solar flare which occurred after the first eruption have injected/accelerated by SEPs since intensity-time profiles are masking the possible effect of the SEPs related to such eruptions. Furthermore, even in some single eruptive SEP events we can find more than one acceleration phase [4,5]. A gradual SEP event might not be due to one single eruption, CME or solar flare. AlSawad $[4,6]$ concludes that the continuity of high intensities due to coronal or interplanetary shock wave might come from several eruptions, which might end in showing one single prolonged intensity-time profile . In such case a continuing intensity - time profile can be due to multi Eruption SEP (MESEP) events . There are two phases of acceleration for high-energy particles of SEP events associated with CMEs. Firstly, when particles can escape the magnetic field in the beginning of the eruption after CME liftoff, and secondly by driven-shock created by a fast CME beyond 3 solar radii, which can lead to continuing acceleration [7].

We have estimated the time and place of the acceleration for the energetic protons injected by two Coronal Mass Ejection (CMEs) associated with MESEP event.

\section{Data analysis}

We used both the low-energy and high-energy particle detectors, LED and HED, of the ERNE instrument on board SOHO [8], to look for SEP events in the energy range $1-100 \mathrm{MeV}$, with 1 minute resolution. ERNE data can be retrieved through the data finder program at( http://srl.utu.fi/erne_data/).Our data analysis is based on calculation the injection time of the energetic protons. Firstly, we adopted the fixed path length method which assumed that the protons have encountered few scattering during their propagation to the Earth along 1.2 AU spiral magnetic field lines which is often used in the event onset studies [9].The injection time (tre) equation [10] is:

$$
t_{r e}=\left(t_{0}-t_{f}\right)+8.3 \min
$$

Where to onset time observed by the detectors, $8.3 \mathrm{~min}$ have been added to represent the time of light to reach the Earth from the Sun, and the flight time (tf) founded by:

$$
t_{f}=s / \beta 1 c
$$

Where $\mathrm{s}$ is the fixed path length for the particles which equal to the distance between the Sun and the detector $(=1.2 \mathrm{AU})$, and $\beta 1$ equal to

$$
\beta 1=\sqrt{1-\left(\frac{p}{B+p}\right)^{2}}
$$

where $\mathrm{p}$ is the proton energy in $\mathrm{MeV}, \mathrm{E}$ is the energy of ERNE Channel in MeV.

The value presumably originates from the path lengths of 1.1-1.3 AU for protons events, and for electrons in all their events. It should be noted that Parker spiral length for a solar wind of velocity 400 $\mathrm{km} / \mathrm{s}$ is below that value, at $1.14 \mathrm{AU}$. We find this difference explainable due to the three -dimensional structure of the magnetic field, may be expected to increase the path length. Secondly, we used the Velocity Dispersion Analysis (VDA) method [11] which assuming that particles in different events might take different path lengths rather than 1.2 AU, assuming that particles with different energies were released simultaneously at the Sun, so the injection time can be determined by [11]:

$$
\mathrm{t}_{\text {ouset }}(\mathrm{E})=\mathrm{t}_{0}(\mathrm{~min} .)+8.33(\mathrm{~min} / \mathrm{AU}) \cdot \mathrm{s} \cdot \mathrm{\beta}^{-1}(\mathrm{E})
$$

Where tonset is the onset time, $\mathrm{s}$ is the path length, and $\beta$ is the inverse velocity of the particles equal to $\beta-1(\mathrm{E})=\mathrm{c} / \mathrm{v}(\mathrm{E})$.

So we determine the onset times for upper 20 proton channels situated at energies (1.63-116) MeV for multi eruption in each events (Fig(1) and (2)) 


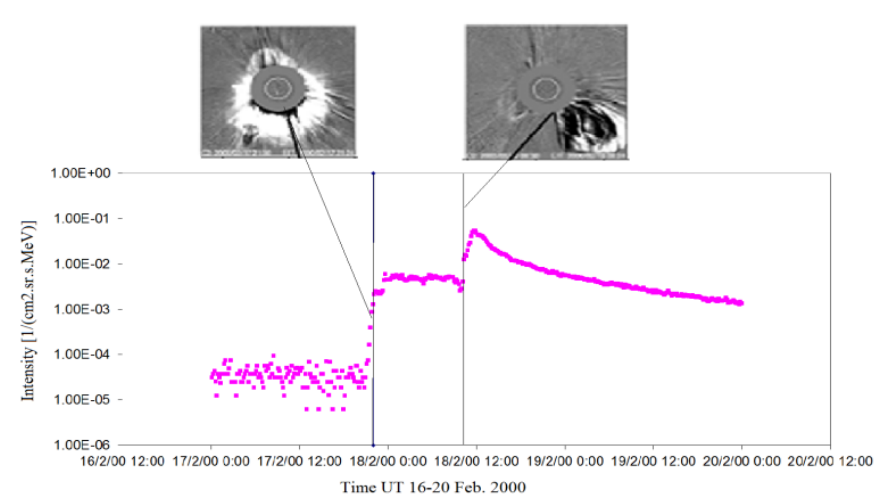

Figure (1): View plots of event 17 Feb.2000, top the LASCO C2 CME observed at 21:30 UT, Bottom the intensity time profile (ERNE).

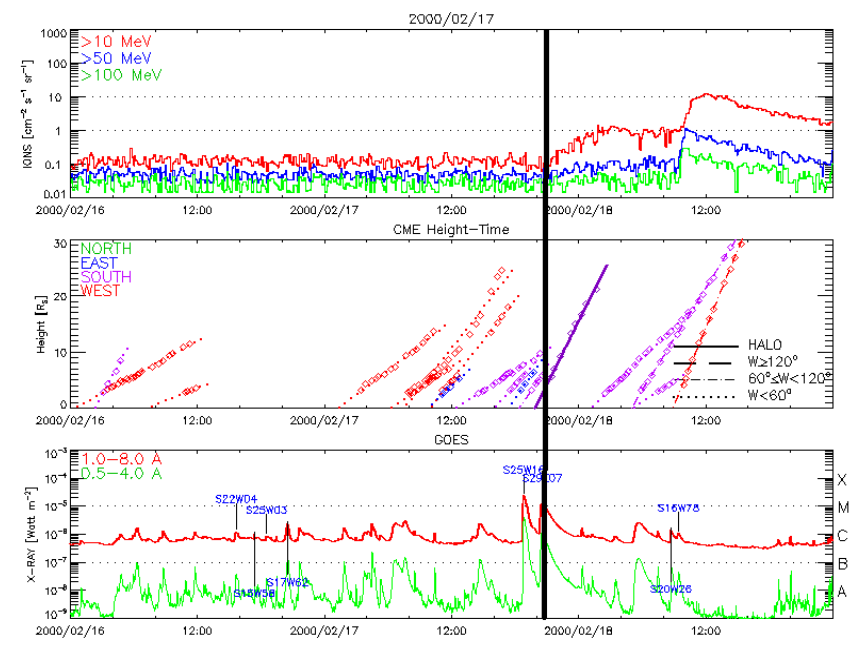

Figure (2): Right panel (top)the intensity time profile(GOES),(middle)CME height- time,(bottom) soft X-ray flare flux, with $\mathrm{H} \alpha$ location notice in blue font over SXR curve.

We employed LASCO catalog to estimate the heliocentric location of the CME for the first injected protons intensity (Fig. 3), where the injection time was estimated by extrapolation to the quadratic fit for height-time measurements.

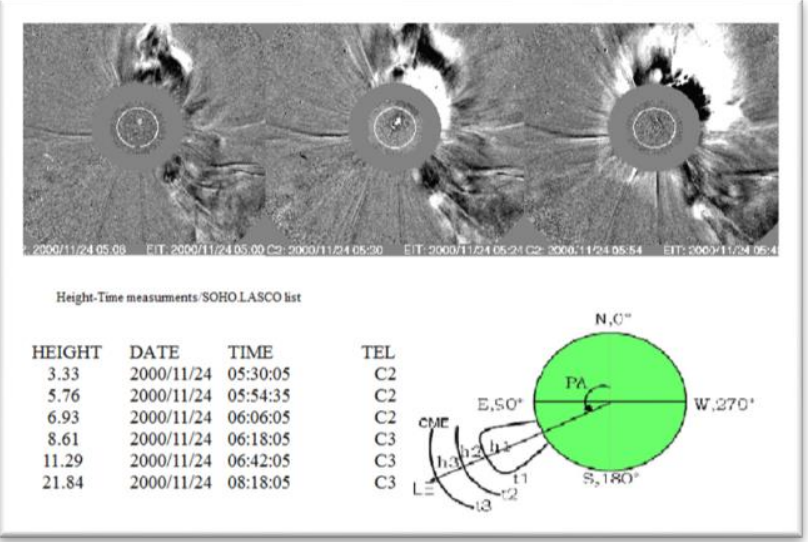

Figure (3): Detailed analysis of CMEs detected in the LASCO C2/C3 images.

\section{$\underline{\text { Results and Discussion }}$}

We have selected two Multi Eruption Solar Energetic Particle (MESEP) events among 268 MESEP events during the solar cycle 23 with angular width $>60^{\circ}$ and linear speed $>500 \mathrm{~km} / \mathrm{sec}$ with intensity above10-3 Cm-2 sr-1 s-1 MeV-1 .Were we take the kinematics of CMEs event from the SOHO/LASCO (Large Angle Spectroscopic Coronagraph)catalog at http: //cdaw.gsfc.nasa.gov/CME_list/UNIV ERSAL/.

We have analyzed the event 17 Feb. 2000 with angular width of $360^{\circ}$, halo CME, linear speed $728 \mathrm{~km} \mathrm{~s}-1$ and acceleration of $-22.9 \mathrm{~ms}-2$ at $21: 30 \mathrm{UT}$ at $5.6 \mathrm{R} \Theta$ with X-ray flare of class(M1.3)at location S29E07, from NOAA active region 8872 that detected by GOES(Fig(2)) . The CME liftoff time is 20:18 UT \pm 11 min taking as an average value for the linear and quadratic fit. The onset time of the event was observed by SOHO/ERNE at 21:05 UT, so by the same way we have record the kinematics of all events. We selected the first rising protons for 1 minutes resolution. The injection time for the first, non-scattered protons that travel with path length 1.2 AU was found to be 20:39 UT. While the injection time of proton by (VDA) was 20:53 UT $\pm 9.7 \mathrm{~min}$ with protons had traveled through path length $1.14 \pm 0.15 \mathrm{AU}$. The heliocentric height of the CME1 that associated with eruption at these time is 1.76 $\mathrm{R} \Theta, 2.84 \mathrm{R} \Theta$ respectively (Table(1)). The second event, on 04 April 2000, associated with halo CME, angular width of $360^{\circ}$, linear speed $1188 \mathrm{~km} \mathrm{~s}-1$ and acceleration of $12.8 \mathrm{~ms}-2$ at 16:32 UT(Fig. 4). Flaring activity is C9.7 class from NOAA active region 8933 at location N16W66 that detected by GOES(Fig.5). The CME left the Sun at 14:47 UT $\pm 05 \mathrm{~min}$. The onset 
time from intensity profile was 15:45 UT for energy 45.5 MeV. The injection time (1.2 method) is 15:20 UT with the heliocentric height of the CME1 at the first protons injection time is $4.38 \mathrm{R} \Theta$, The injection time with VDA method is $15: 18 \mathrm{UT} \pm 6.1 \mathrm{~min}$ which have traveled with path length $1.28 \pm 0.120 \mathrm{AU}, \mathrm{CME}$ location at 5.1 $\mathrm{R} \Theta$ (Table (1)).

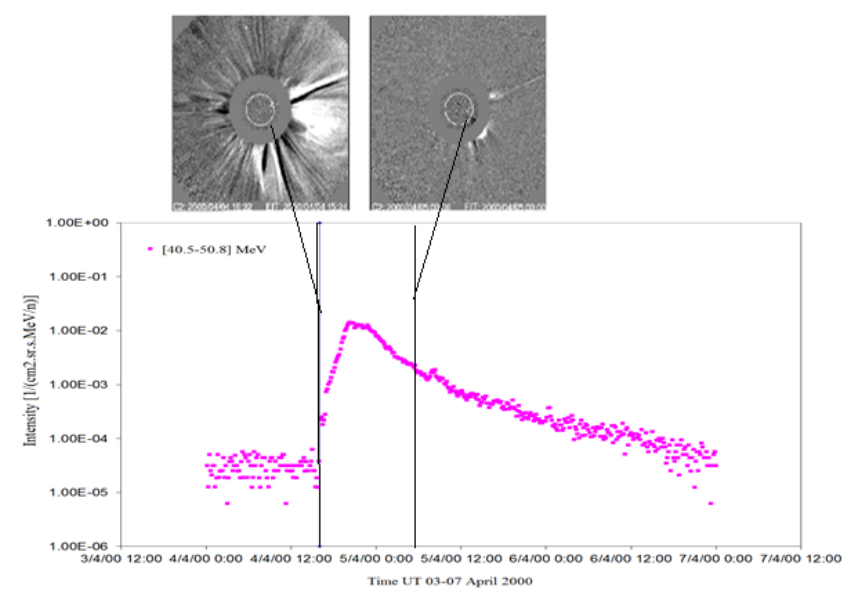

Figure(4): View plots of event 04-07 April 2000, the top of the LASCO C2 CME observed at 21:30 UT, the bottom of the intensity time profile(ERNE).

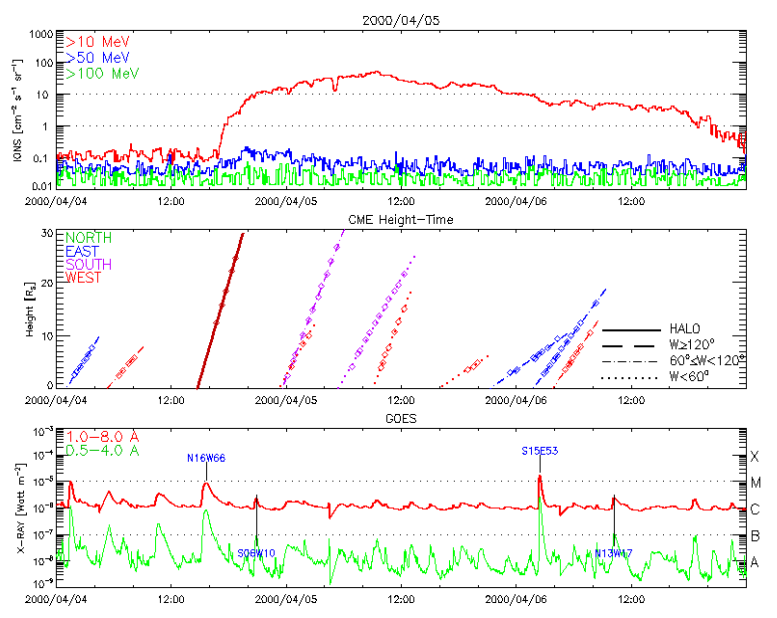

Figure (5): Right panel (top)the intensity time profile(GOES),(middle)CME height-time,(bottom) soft $\mathrm{X}$-ray flare flux, with $\mathrm{H}_{\alpha}$ location notice in blue font over SXR curve.

With this analysis for the events we notice that the CME heliocentric height was located $\sim 1-5$ solar radii for first proton injection time (Fig.(6)).
Table(1): Injection time (1.2 AU \&VDA) methods and CMEs heights

\begin{tabular}{|c|c|c|c|c|c|c|}
\hline Date & $\begin{array}{c}\text { Injection } \\
\text { time(1.2) } \\
\text { UT }\end{array}$ & $\begin{array}{c}\text { Injection } \\
\text { time(VDA) } \\
\text { UT }\end{array}$ & $\begin{array}{l}\text { Height } \\
(1.2) \\
\text { R९ }\end{array}$ & $\begin{array}{c}\text { Height } \\
\text { (VDA) } \\
\text { RO }\end{array}$ & $\begin{array}{l}\text { Height of } \\
\text { CME2 } \\
\text { R९ }\end{array}$ & $\begin{array}{l}\text { Height of } \\
\text { CME1 at } \\
\text { liftoff of } \\
\text { CME2 RO }\end{array}$ \\
\hline 17.02 .00 & $20: 39$ & $20: 53 \pm 9.7 \min$ & 1.76 & 2.84 & 2.44 & 30.2 \\
\hline 04.04 .00 & $15: 20$ & $15: 18 \pm 6.1 \min$ & 4.38 & 5.1 & 0.923 & 62.4 \\
\hline
\end{tabular}

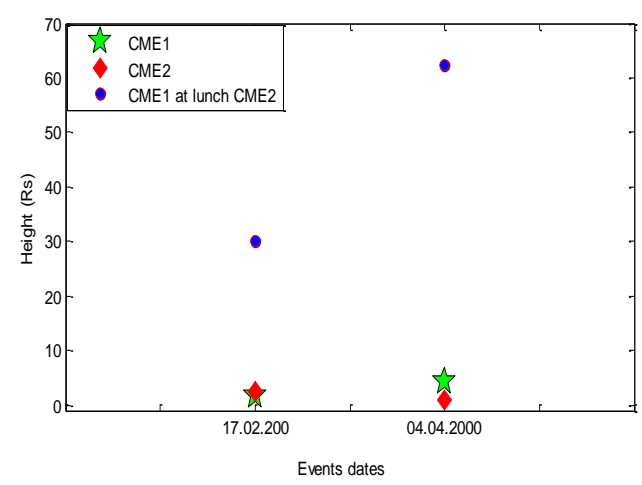

Figure(6): heliocentric height of(CME1 \& CME2), and the height of CME1 at the lunch of CME2.

\section{Conclusions}

By calculating the injection time of the first energetic proton with fixed path length method(1.2 AU) and Velocity Dispersion Analysis (VDA) method, assuming that particles with different energies were released simultaneously at the Sun, we found that:

1- CMEs were located at height of 1-5 solar radii.

2- All of the SEP are associated with coronal mass ejection (CME) and solar flare.

3- We found that in both methods the bulk of the acceleration occur during the impulsive phase near the Sun.

\section{$\underline{\text { References }}$}

1. Klecker B., Cane H. V., Dalla S., Heber B., Kecskemety K., Klein K.-L., Kota J., Kucharek H., Lario D., Lee M. A., Popecki M.A., Posner A., Rodriguez-Pacheco J., Sanderson T., Simnett G. M., and Roelof E.C., Space Sci. Rev. ,123, 217, (2006).

2. Sheeley N.R. Jr., Howard R.A., and Michels D.J., J. Geophys. Res., 90, 163-175 (1985). 
3. Schwenn R., space weather :the solar perspective. Living Reviews in solar physics, 3,(2006).

4. Al-Sawad A., Torsti J., Kocharov L., and HuttunenHiekinmaa K. JGR, V. 111, A10S90 (2006).

5. Bombardieri D.J., Duldig M.L., Michael K.J., and Humble J.E. ApJ, V. 644, p. 565-574 (2006).

6. Al-Sawad, H. Allawi, W. Al-Ramdhan, and E. Valtonen, Astrophysics and Space Sciences Transactions, 8, 1-5, (2012 ).

7. Kocharov L., and Torsti J. Solar Physics, 207, 149157 (2002).

8. Torsti, J., Valtonen E., Lumme M., Peltonen P., Eronen T., Louhola M., Riihonen E., Schultz G., Teittinen M., Ahola K., Holmlund C., Kelhä V., Leppälä K., Ruuska P., and Strömmer E., Sol. Phys., 162, 505, (1995).

9. Cane, H. V., von Rosenvinge T. T., Cohen C.M. S., and Mewaldt R. A., Geophys. Res. Lett., 30(12), 8017, (2003).

10.Torsti J., Kocharov L., Teittinen M. , Anttila A. , Laitinen L., Mkel P., Riihonen E., Vainio R., and Valtonen E. , J. Geophys. Res., 104, 9903, (1999).

11.Huttunen-Heikinmaa, K., E. Valtonen, and T. Laitinen, Astron. Astrophys.,442, 673-685, (2005). 